\title{
Soluble Liver Antigen IgG Antibody Measurement
}

National Cancer Institute

\section{Source}

National Cancer Institute. Soluble Liver Antigen Ig G Antibody Measurement. NCI

Thesaurus. Code C122150.

The determination of the amount of soluble liver antigen Ig G antibody present in a sample. 